Original Research Paper

\title{
Jenis-Jenis Makroalga Epifit Pada Budidaya (Kappaphycus alvarezii) di Perairan Teluk Gerupuk Lombok Tengah
}

\author{
Mursal Ghazali $^{1 *}$, Mardiana $^{1}$, Menip $^{1}$, Bangun $^{2}$ \\ ${ }^{1}$ Program Studi Biologi, Fakultas Matematika dan Ilmu Pengetahuan Alam, Universitas Mataram \\ ${ }^{2}$ Balai Perikanan Budidaya Laut Lombok
}

\section{Article history}

Received: 29 Oktober 2018

Revised: 6 November 2018

Accepted: 24 November 2018

Published: 26 November 2018

*Corresponding Author:

Mursal Ghazali,

Program Studi Biologi,

Fakultas Matematika dan Ilmu

Pengetahuan Alam, Universitas

Mataram, Indonesia.

Email:

mursalghazali@unram.ac.id
Abstract: Epiphytes are organisms that attach to other organisms to support their growth and development. One type of epiphytes that has a negative impact on the host is algae (macroalgae). This algae is a competing organism for cultivation algae (Kappaphycus alvarezii). This research was conducted From May to October 2017 in Gerupuk Bay, Central Lombok. The aim of the research is to find out the types of macroalgae epiphytes on macroalgae kappaphycus alvarezii. This research was conducted using exploratory methods by taking seaweed samples overgrown with epiphytes, the research data obtained were descriptive analisys. As supporting data, environmental parameters are measured including temperature, $\mathrm{pH}$, salinity, DO, phosphate, and NH4. Based on the results of exploration found 13 species of epiphytic algae in kappaphycus alvarezi cultivation, namely: Chaetomorpha linum, Chaetomorpha linum, Cladophora dalmatica, Acanthophora spicifer, Batrachospermum sp, Callithamnion sp., Caulachantus ustulatus, Ceramium sp, Hypnea spinnosa, Hypnea spinella, Hypnea sp, Polysiphonia brodiaei, Spyridia filamentosa. The type of epiphytes found that grows in both cultivation methods and some others are found only in one method. Meanwhile, data on environmental parameters are in the optimal range for macroalgae growth.This data is expected to be used as a consideration for the cultivateddevelopment in the Gerupuk Bay cultivation center.

Keywords : Macroalgae, Epiphytes, Aquaculture, Kappaphycus alvarezii

Abstrak: Epifit merupakan organisme yang menempel pada organisme lain untuk menunjang pertumbuhan dan perkembangannya. Salah satu jenis epifit yang memberikan dampak negative bagi inangnya ialah alga (makroalga).Alga ini menjadi organisme kompetitor bagi alga budidaya (Kappaphycus alvarezii).Penelitian ini dilaksanakan pada bulan Mei sampai Oktober 2017 di Perairan Teluk Gerupuk Lombok Tengah.Penelitian ini bertujuan untuk mengetahui jenis-jenis makroalgae epifit pada makroalga budidaya kappaphycus alvarezii yang di budidaya di perairan Teluk Gerupuk Lombok Tengah.Penelitian ini dilakukan dengan menggunakan metode eksploratif dengan mengambil sampel rumput laut yang ditumbuhi epifit, data penelitian yang didapatkan dianalisis secara deskriptif.Sebagai data pendukung dilakukan pengukuran parameter lingkungan meliputi suhu, $\mathrm{pH}$, salinitas, DO, Posfat, dan NH4. Berdasarkan hasil eksplorasi didapatkan 13 spesies alga epifit pada budidaya kappaphycus alvarezi yaitu: Chaetomorpha linum, Chaetomorpha linum, Cladophora dalmatica, Acanthophora spicifer, Batrachospermum sp, Callithamnion sp., Caulachantus ustulatus, Ceramium sp, Hypnea spinnosa, Hypnea spinella, Hypnea sp, Polysiphonia brodiaei, Spyridia filamentosa.Jenis epifit yang ditemukan ada yang tumbuh pada kedua metode budidaya dan sebagian yang lain hanya ditemukan pada salah satu metode saja. Sementara itu, data parameter lingkungan berada pada kisaran optimal untuk perttumbuhan makroalga. Data hasil penelitian diharapkan dapat dijadikan sebagai pertimbangan pengembangan budidaya di sentra budidaya Teluk gerupuk.

Kata Kunci : Makroalga, Epifit, Budidaya, Kappaphycus alvarezii 


\section{Pendahuluan}

Makroalga merupakan tumbuhan yang belum dapat dibedakan bagian-bagian spesifik seperti akar, batang dan daun, akan tetapi makroalga ini memiliki ciri spesifik yang dapat membedakannya dengan tumbuhan lain yaitu thallus. Makroalga memiliki berbagai macam bentuk, ukuran dan warna yang dijadikan sebagai dasar pengelompokan. Makroalga juga memiliki tempat hidup yang bermacam-macam meliputi serpihan karang, karang berlumpur, karang mati, pasir berlumpur, mangrove (Ghazali et.al., $2018^{\mathrm{a}}$; Ghazali et.al., 2018 ), lamun dan tidak jarang ditemukan pula hidup dan melekat pada makroalga lainnya.Selain ditemukan hidup bebas pada daerah intertidal dan subtidal,beberapa jenis makroalga dibudidayakan secaraluas oleh masyarakat.Budidaya dilakukan sebagai upaya memenuhi kebutuhan pasar yang terus meningkat.Meskipun demikian, terdapat beberapa kendala dalam kegiatan budidaya, salah satunya ialahkeberadaan epifit Ghazali et al, (2017).

Epifit adalah tumbuhan yang hidup menempel pada tumbuhan lain sebagai penopang atau inang, umumnya berukuran lebih kecil dan tidak memberikan efek negative secara langsung pada inangnya. (Kusumaningrum, 2008). Epifit berbeda dengan parasit, epifit tidak sepenuhnya bergantung pada tumbuhan induknya akan tetapi dapat hidup mandiri, lepas dari tanah sebagai penyangga dan penyedia hara bagi kehidupannya maupun dari hara yang disediakan tumbuahan lainnya.Beberapa jenis makroalga sering kali ditemukan hidup dan melekat pada tumbuhan lain sebagai epifit, salah satunya yaitu pada talus alga budidaya Kappaphycus alvarezii.

Keberadaaan epifit pada talus alga budidaya tidak memberikan dampak negatif secara langsung.Tetapi, keberadaan epifitdapat menjadi competitor bagi inangnya.Epifit dan inang memiliki kebutuhan yang sama untuk memenuhi kebutuhanmelalui proses fotosintesis, sehingga keberadaanepifit pada talus akan berpengaruh terhadap keberlangsungan hidup Kappaphycus alvarezii (Arisandi et al., 2013). Pengaruh tersebut diantaranya ialah mengganggu atau menghalangi Kappaphycus alvarezii budidaya untuk menyerap nutrisi dan cahaya.Bahkan keberadaan epifit dapat mengundang kehadiran organismeyang merugikan.Selain itu, Nurdiana et al, (2016) mengatakan bahwa sebagian makroalga epifit bersifat parasit.Pada sebagian alga, holfast dapat menembus talus inang dan menyerap nutrisi dari inangnya.Kondisi ini dapat mengakibatkan gagal panen pada kegiatan budidaya.

Salah satu sentra budidaya yang yang sering mengalami gagal panen akibat adanya serangan epifit ialah sentra budidaya Teluk Gerupuk, Lombok Tengah. Inventarisasi dan identifikasi makroalga epifit sangat sering dilakukan oleh peneliti sebelumnya,akan tetapi belum ada yang melakukakan penelitian yang spesifik tentang jenis epifit yang melekat pada talus Kappaphycus alvarezii yang berada di teluk gerupuk.

Penelitian ini bertujuan untuk megidentifikasi jenis makroalga epifit yang terdapat pada budidaya rumput laut jenis Kappaphycus alvarezii metode tanam rakit dan metode tanamlongline yang terdapat di Balai Budidaya Laut Lombok Stasiun Gerupuk, Lombok Tengah.

\section{Bahan dan Metode}

\section{Bahan Penelitian}

Bahan-bahan yang digunakan dalam penelitian ini ialah Formalin 4\% dan alkohol $70 \%$ yang digunakan sebagai pengawet untuk menjaga kondisi talus tetap utuh. Akuades untuk melarutkan formaloin dan alcohol serta mencuci alga dari kotoran yang menmpel.

\section{Metode Penelitian}

Penelitian ini dilaksanakan pada bulan Maret sampai November 2017, bertempat di Balai Perikanan Budidaya Laut Lombok (BPBL) yang terletak di Dusun Gerupuk, Desa Sengkol, Kecamatan Pujut, Kabupaten Lombok Tengah dan Laboratorium Imunobiologi Universitas Mataram. Pengambilan sampel dilakukan di BBL Lombok Stasiun Gerupuk.Sementara itu, idetifikasi dan pengambilan gambar dilakukan di Laboratorium Imunobiologi.

Metode sampling yang digunakan pada penelitian ini ialah metode eksploratif. Pengambilan sampel dilakukan padadua metode budidaya yaitu rakit bambu dan long-line. Sampel yang diambil merupakan sampel rumput laut yang terserang oleh epifit. Pengambilan sampel dilakukan sebanyak 3 kali selama penelitian.Sampel yang didapatkan kemudian dibawa ke laboratorium untuk identifikasi. Untuk 
menjaga keutuhan talus, maka dilakukan pengaetan menggunakan alkohol $70 \%$.

Selain itu, dilakukan juga pengambilan data parameter lingkungan sebagaidata pendukung. Parameter lingkungan yang diambil ialah NH4, phosfat, suhu, $\mathrm{pH}$, salinitas dan oksigen terlarut (DO).

Makroalga epifit yang didapatkan diperlakukan dengan cara yang berbeda, tergantung ukuran talusnya.Makroalga epifit yang memiliki ukuran talus besar langsung diidentifikasi di lapangan untuk menghindari kerusakan. Sementara itu, epifit yang berukuran kecil dibawa ke laboratoriumImmunologi Universitas Mataram untuk diamati dibawah mikroskop. Data morfologi yang didapatkan digunakan sebagai dasar identifikasi jenis epifit yang ditemukan.

\section{Hasil dan Pembahasan}

\section{Jenis makroalga epifit}

Jenis makroalga epifit yang ditemukan menempel pada permukaan thalus Kappaphycus alvarezii secara umum terdiri dari dua filum yaitu Chlorophyta dan Rhodophyta.Jumlah spesies makroalgae epifit lebih banyak berasal dari filum Rhodophyta dibandingkan dengan Chlorophyta.Anggota filum Chlorophyta yang ditemukan hanya berjumlah 3 spesies yaitu Cladophora sp., Chaetomorpha linum, dan Chaetomorpha crassa.Semantara itu, anggota Rhodophyta yang ditemukan sebanyak10 yaitu Polysiphonia brodiaei, Ceramium sp, Callithamnion sp, Batrachospermum sp.spyridia filamentosa, Acanthophora spicifera, , Caulachantus ustulatus, Hypnea spinnosa, Hypnea spinella and Hypnea sp. Jumlah spesies yang ditemukan lebih banyak dibandingkan dengan epifit yang ditemukan pada sentra budidaya Dusun Pengantap, Lombok Barat. Ghazali dan Nikmatullah (2015), hanya menemukan 4 spesies makroalga epifit yang menempel yaitu Ulva sp, Cladopora sp, Ceramium sp dan Polisiponia sp.

\section{Filum Chlorophyta}

Chaetomorpha linummemiliki Ciri umum adalah thallusnya yang berbentuk helaian seperti rambut panjang dan sering ditemukan melilitit dan menggumpal pada thallus Kappaphycus alvarezii, berwarna kehijauan dan ketika di amati dibawah mikroskop chaetomorpha ini memiliki buku-buku yang cukup rapat.

Chaetomorpha crassa tidak jauh berbeda dengan Chaetomorpha linum, hanya yang membedakannya yaitu dari segi ukuran dan sekatsekat yang dimiliki.Ciri umum adalah thallusnya yang berbentuk helaian seperti rambut panjang dan sering ditemukan melilitit dan menggumpal pada thallus Kappaphycus alvarezii, berwarna kehijauan dan ketika diamati dibawah mikroskop Chaetomorpha crassa ini memiliki segmensegmen yang cukup rapat.

Cladophora dalmatica.merupakan alga hijau (Chlorophyta) yang talusnya lentur menyerupai rambut dengan bagian ujung talus bercabang dua (dichotomous). Bentuk thallusnya akan membuat alga ini mudah untuk melilit ganggang budidaya (Ghazali et.al., 2017).

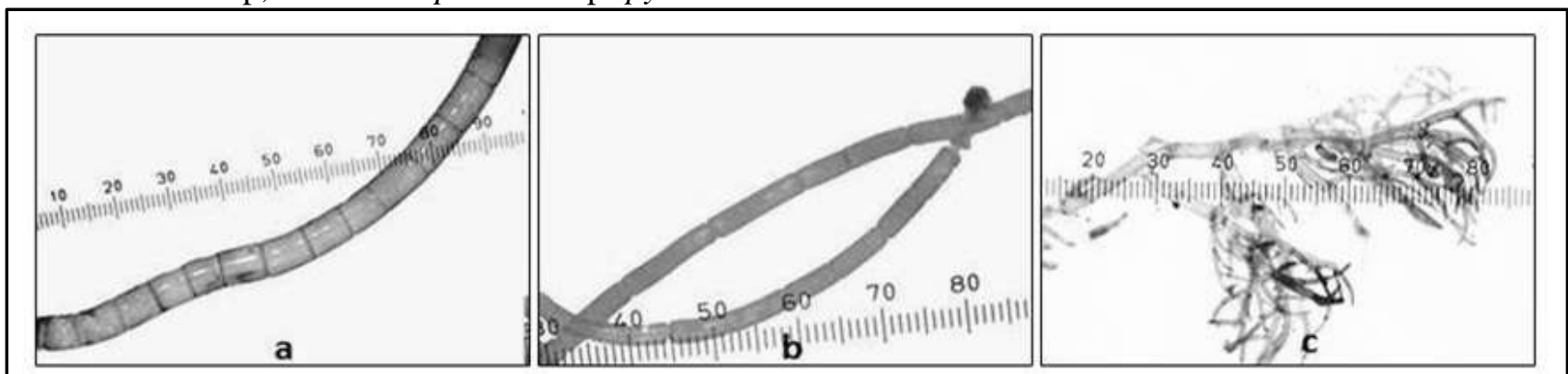

Gambar 1. Makroalga hijau epifit yang ditemukan pada thalus Kappaphycus alvarezii Keterangan: a. Chaetomorpha linum, b. Chaetomorpha crassa, c. Cladoporadalmatica.

\section{Filum Rhodophyta}

Acanthophora spicifera adalah alga Rhodophycea dengan distribusi luas di seluruh daerah tropis dan subtropis. Persebaran ini terjadi pada beragam substrat, dari dasar keras, sebagian epifit pada ganggang lainnya, atau sebagai alga detritif hidup bebas. Algae ini sering sebagai komponen biomassa alga detritif.A. spicifera memiliki holdfast berbentuk besar dan tidak beraturan untuk menempel pada substrat keras. Dari pegangan atau holdfast, thalus tegak dan bercabang. Cabang utama memiliki cabang cabang pendek dan menentu yang tidak beraturan dan berputar. Cabang-cabang itu seperti kail, rapuh dan fragmennya mudah di bawa oleh gelombang. Warna sangat bervariasi, dan biasanya berwarna 
merah, ungu, atau coklat. A. spicifera tumbuh tegak sampai kira-kira $25 \mathrm{~cm}$ (Global Invasive Spesies Database, $2015^{\mathrm{a}}$ ).

Batrachospermum sp Termasuk makroalga yang memiliki thallus yang lunak, percabangan thallus berada pada ruas-ruas thallus.Percabangan muncul pada lingkaran-lingkaran dari buku-buku thallus tersebut.Distribusi yang cukup luas baik pada suhu yang sedang hingga tropis.

Callithamnion spmerupakan makroalga yang tergolong ke dalam ordo Ceramiales yang merupakan salah satu genus dari Phylum Rhodophyta.Thallus menyerupai tumbuhan tingkat tinggi yang memiliki percabangan hampir di seluruh bagian thallusnya.Percabangan tersebut tampak seperti benang/ berfilamen.

Ceramiumsp memilikipermukaan talus agak kasar, sel medula parenkimatous dengan sel-sel rapat atau berongga. Sel perisentral bulat tidak baraturan dan berukuran lebih pendek dari sel aksial.tipe thallus filament dengam kortikasi sebagian. Percabangan rimbun dan berseling tak beraturan (Ghazali et.al., 2017)..

Caulachantus ustulatus merupakan salah satu spesies dari Rhodophyta.Caulachantus ustulatus memiliki bentuk thalus silindris, panjang dan bercabang-cabang menyerupai tanduk dengan warna halusnya berwarna merah (Ghazali et.al., 2017).

Hypnea spinnosa merupakan salah satu contoh spesies dari Rhodophyta (ganggang merah).Bentuk Thallus silindris, percabangan alternate, terdapat duri-duri cabang yang pendek rnenyerupai taji atau tanduk. Rumpun rimbun dan berekspansi ke berbagai arah.Ukuran thallus kecil. Warna thallus hijau kekuningkuningan atau kuning-pucat (Ghazali et.al., 2017).

Hypnea spinella memiliki thalus seperti bantalan dengan sumbu cabang bercabang tegak lurus yang menancap di sana-sini, di atas bantal sehingga tidak teratur secara garis besar, biasanya setinggi $2,5 \mathrm{~cm}$. Sumbu silindris, kurang dari 400 $\mathrm{mm}$ diam. Di tengah dari dasar ke puncak, cabang sebagian besar dikotomis atau dibagi secara tidak teratur. Keterikatan sekunder sering terjadi, jika ada, terbentuk antara cabang di pertengahan sampai bagian atas thallus. Cabang cabang spinelike pendek, bervariasi dalam kelimpahan, basisnya agak terpotong dan apice tajam menunjuk. Tetrasporangial sori sesekali mencolok pada ujung cabang yang bengkak, tapi pada tanaman yang sama sori juga bisa ditemukan di dekat base, girdling branchlets.
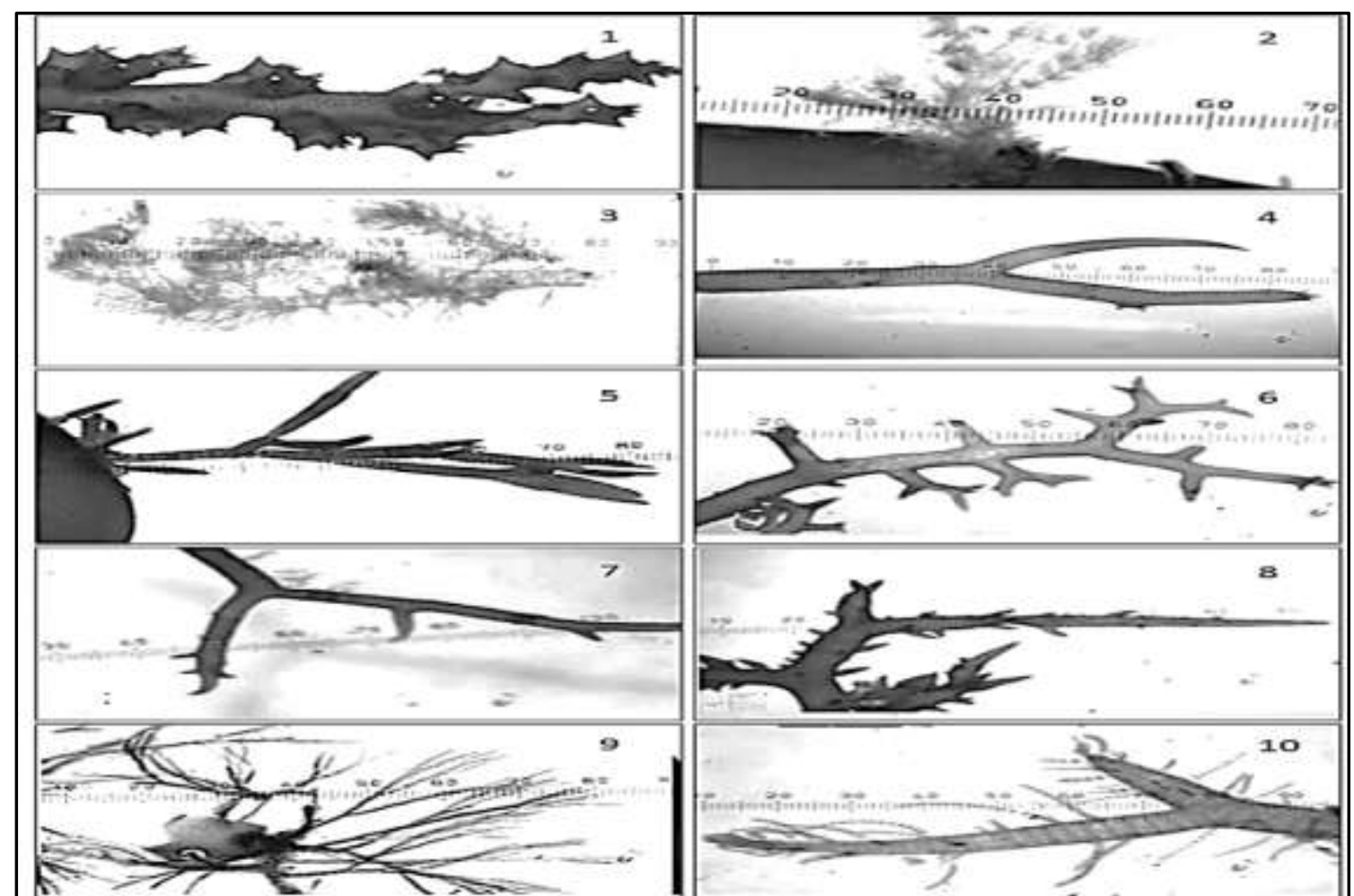

Gambar 1. Jenis-jenis makroalga yang ditemukan pada talusKappaphycus alvarezii di sentra budidaya rumput laut teluk gerupuk kabupaten Lombok Tengah. Keterangan: 1. Acanthophora spicifera;2. Batrachospermum sp; 3. Callithamnion sp.; 4. Caulachantus ustulatus; 5. Ceramium sp; 6. Hypnea spinnosa; 7. Hypnea spinella; 8. Hypnea sp; 9.Polysiphonia brodiaei;10.Spyridia filamentosa 
Hypnea $s p$ Juga termasuk dalam Rhodophyta memiliki talus silindris, panjang dan berumbai.Bentuk thalus silindris dan bercabang dengan ujung thalus runcing.Percabangan tidak teratur membentuk rumpun yang rimbun, sehingga tampak menggumpal.Ukuran thalusnya kecil dan berwarna merah.Algae ini tumbuh tersebar luas di perairan tropis sampai perairan subtropis.

Polysiphonia brodiaei adalah alga yang berfilamen merah. Polysiphonia brodiei adalah alga merah dari famili Rhodomelaceae dalam ordo Ceramiales (Rhodophyta). P. brodiei umumnya memiliki tinggi $5-25 \mathrm{~cm}$ bahkan sampai setinggi $40 \mathrm{~cm}$ (Global Invasive Spesies Database, 2015 ${ }^{\mathrm{b}}$ ), warna thalus coklat tua kemerahan sampai merah tua dan berwarna ungu, serta bercabang banyak dan tidak teratur. Tanaman melekat pada substrat oleh banyak thalus dan sumbu thalus bercabang bercabang yang berkembang dari dasar sumbu muda. Sumbunya sangat lembut dan lembek saat muda, dan menjadi lebih kencang dan lentur saat lebih tua.Cabang dibentuk di axils trichoblasts.Sistokarsit memiliki tangkai yang pendek, dan berongga dengan sel ostiolar sedikit meningkat.Morfologi spesies ini sangat bervariasi dengan kondisi lingkungan.Tanaman yang ditemukan di tepian intertidal yang lebih rendah atau struktur terapung memanjang dan lembek dengan garis besar silinder ke lateral, sedangkan di kolam pantai bagian atas, tanaman tersebut berumbai-rumbai dan memiliki garis besar piramid.dapat tumbuh pada berbagai substrat seperti batu, tali, kayu, beton dan logam.

Spyridia filamentosamemiliki Thallus berwarna abu-abu sampai abu-abu kemerahan, kadangkadang berwarna merah kecoklatan, tinggi 7-18 $\mathrm{cm}$, thalusnya lentur dan lembut, percabangan thalus tidak teratur, terdapat banyak bercabang di semua sisi dengan cabang yang lebih panjang dan pendek bercampur, dengan satu sampai beberapa sumbu (Won et.al., 2005). Ujung Holdfastnya diskoid, selanjutnya berserat atau stoloniferous dan terjerat; algae ini epilitik atau epifit pada berbagai alga dan lamun yang lebih besar. Struktur Sumbu dan cabang yang lebih besar bersifat kokoh. Sumbu meruncing ke cabang yang lebih kecil lateral yang timbul dari sel periaxial atau secara adventif dari sel korteks. Segmen biasanya didefinisikan dengan jelas pada cabang, panjangnya bervariasi dan proporsi.

\section{Jenis Epifit Pada Inang Yang Dibudidayakan dengan MetodeRakit dan Longline}

Kappaphycus alvarezii merupakan makroalga yang sangat umum dibudidayakan oleh masyarakat pesisir Indonesia (WWF, 2014). Makroalga ini memiliki banyak manfaat baik secara langsung maupun tidak langsung.Pembudidayaan rumput laut tergolong mudah dan murah untuk dilakukan. Meskipun demikian, bukan berarti bahwa budidaya rumput laut tidak memiliki resiko. Berbagai faktor lingkungan sering menjadi faktor utama kegagalan budidaya rumput laut.Selain itu, keberadaan predator dan epifit memiliki peranan yang sangat negatif terhadap pertumbuhan rumput laut (Ghazali, 2017). Keberadaan epifit mampu menyebabkan gagal panen total pada musim tertentu. Keberadaan epifit secara langsung mungkin tidak mengambil nutrisi dari rumput laut yang dibudidayakan (Arisandi, 2013).Tetapi, keberadaannya mampu menghalangi permukaan talus untuk mendapatkan sinar matahari.Kondisi ini membuat permukaan talus menjadi lebih rapuh dan rawan terserang bakteri. Keberadaan bakteri akan semakin memperparah tingkat kegagalan budidaya rumput laut (Fitrian, 2015).

Tabel 1.Jenis alga epifit yang ditemukan pada permukaan talus Kappaphycus alvarezii yang dibudidayakan dengan metode rakit bamboo dan long-line.

\begin{tabular}{lllll}
\hline \multirow{2}{*}{ No } & \multirow{2}{*}{ Filum } & Spesies & \multicolumn{2}{l}{ Metode Budidaya } \\
\cline { 3 - 4 } & & Rakit & Long-line \\
\hline 1 & Cholophyta & Chaetomorpha linum & + & + \\
2 & & Chaetomorpha crassa & + & + \\
3 & \multirow{2}{*}{ Rhodophyta } & Cladoporadalmatica & + & + \\
4 & Acanthophora spicifera & + & - \\
5 & & Batrachospermum sp. & - & - \\
6 & Callithamnion sp & + & - \\
7 & Caulachantus ustulatus & + & + \\
8 & Ceramium sp & - & - \\
9 & Hypnea spinnosa & + & - \\
10 & & Hypnea spinella & + & \\
\hline
\end{tabular}




\begin{tabular}{lllll}
\hline \multirow{2}{*}{ No } & \multirow{2}{*}{ Filum } & Spesies & \multicolumn{2}{c}{ Metode Budidaya } \\
\cline { 3 - 4 } & & Rakit & Long-line \\
\hline 11 & Hypnea sp & + & + \\
12 & Polysiphonia brodiaei & + & + \\
13 & Spyridia filamentosa & + & + \\
\hline
\end{tabular}

Salah satu lokasi budidaya rumput laut yang ada di Pulau Lombok ialah sentra budidaya rumput laut Teluk Gerupuk. Pada sentra budidaya ini, dilakukan budidaya rumput laut dengan dua metode yaitu rakit bambu dan long-line.Perbedaan penggunaan metode budidaya ini terletak pada kedalaman lokasi, ketahanan bahan dan kuat arus pada lokasi budidaya.Metode rakit umumnya digunakan pada lokasi dengan arus tidak terlalu kuat pada lokasi dengan kedalaman maksimal 10 m. Sementara itu, metode long-line digunkan pada lokasi yang memiliki arus relative keras pada lokasi dengan kedalaman 5 sampai $15 \mathrm{~m}$. Teknik pemanaman yang sedikit berbeda menyebabkan talus rumput laut pada metode rakit bambu memiliki pergerakan lebih kaku dibandingkan dengan longline.Kondisi ini akan menyebabkan perbedaan kecepatan organism easing untuk menempel pada permukaan talus rumput laut yang dibudidyakan, termasuk epifit.

Jenis epifit yang ditemukan pada metode rakit bambu lebih banyak dibandingkan dengan epifit yang ditemukan pada metode long-line.Pada rakit bamboo ditemukan sebanyak sebelas jenis epifit, sementara itu pada metode long-line ditemukan hanya 8 jenis saja.Dari keseluruhan epifit yang ditemukan, terdapat 6 jenis epifit yang ditemukan pada dua metode budidaya. Keenam jenis terbut ialah Chaetomorpha linum,Chaetomorpha crassa, Cladophorasp, Hypnea sp, Polysiphonia brodiaei dan Spyridia filamentosa. Selain ditemukan pada kedua metode budidaya, terdapat juga epifit yang hanya ditemukan pada salah satu metode budidaya saja.Salah satu contohnya ialah Acantophora specifera. Alga ini hanya ditemukan pada metode rakit.

Menurut Aslan (1998) pertumbuhan rumput laut dipengaruhi oleh factor lingkungan seperti cahaya, subtrat, $\mathrm{pH}$, salinitas , suhu, gerakanair, zat hara (nitrat dan fosfat).Secara umum faktor fisik dan lingkungan yang diukur memiliki kisaran yang optimal bagi pertumbuhan rumput laut. Dengan kondisi ini maka faktor lingkungan yang diukur tidak memiliki pengaruh terhadap kehadiran epifit pada talus rumput laut yang dibudidaya dengan metode yang berbeda. Oleh sebab itu, terdapat kemungkinan faktor lain yang tidak terukur yang menjadi penyebab perbedaan epifit yang tumbuh. Salah satu factor lain tersebut ialah kuat arus. Kuat arus memiliki peranan yang sangat besar terhadap kecepatan suatu organisme menempel pada permukaan rumput laut.Semakin kuat arus suatu perairan, maka peluang penempelan pada talus rumput laut semakin rendah. Selain itu, pada metode rakit bambu tali ris dipasang kencang sedangkan pada metode long-line tali ris dipasang kendor. Kondisi ini menyebabkan talus rumput laut pada metode long-line bergerak lebih bebas dan memperkecil peluang epifit untuk menempel.

Tabel 1. Pengukuran kualitas air di kawasan budidaya rumput laut Kappaphycus alvarezii strain tembalang metode tanam rakit bambu dan longline di Teluk Gerupuk Lombok tengah.

\begin{tabular}{lllll}
\hline No & Parameter & $\begin{array}{l}\text { Hasil } \\
\text { Pengukuran }\end{array}$ & Kisaran Kelayakan & Refrensi \\
\hline 1. & NH4 & 0,136 & $0,1-3,5$ & Efendi, 2003 \\
2. & Phospat & 0,017 & $0.07 \mathrm{mg} /$ liter & Putinella (2001) \\
3. & Suhu & 25,4 & $24-30^{\circ} \mathrm{C}$ & Bakosurtanal (1999) \\
4. & Ph & 7,5 & $7,0-8,5$ & Barus (1996) \\
5. & Salinitas & 33 & $28-35$ & Aslan (1998) \\
6. & DO & 6,2 & $(>6,5)$ & Odum (1971) \\
\hline
\end{tabular}

\section{Kesimpulan}

Berdasarkan hasil koleksi rampel
dilapangan dan identifikasi yang dilakukan didapatkan13 spesies makroalga epifit.3 spesies merupakan anggota dari alga hijau (Chlorophyta) dan 10 spesies merupakan anggota dari alga merah (Rhodophyta). Anggota filum Chlorophyta yang ditemukanyaituCladophora sp., Chaetomorpha 
linum, dan Chaetomorpha crassa. Semantara itu, anggota Rhodophyta yang ditemukan yaitu Polysiphonia brodiaei, Ceramium sp, Callithamnion sp, Batrachospermum sp.spyridia filamentosa, Acanthophora spicifera, Caulachantus ustulatus, Hypnea spinnosa, Hypnea spinella and Hypnea sp. Dari Jenis epifit yang ditemukan, terdapat epifit yang ditemukan tumbuh pada kedua metode tersebut dan sebagian yang lain hanya ditemukan pada salah satu metode saja. Sementara itu, data parameter lingkungan berada pada kisaran optimal untuk pertumbuhan makroalga.

\section{Ucapan Terima Kasih}

Terima Kasih kami sampaikan kepada Kepala Balai Budidaya Laut Lombok beserta jajaran yang telah memberikan izin dan membantu kami dalam melaksanakan kegiatan penelitian.

\section{Daftar Pustaka}

Anggadiredja J, Purwoto A dan Istini S. 2011. Seri Agribisnis Rumput Laut. Penebar Swadaya. Jakarta.

Arisandi A., Farid A., Wahyuni E.A., Rokhmaniati S., 2013,Dampak Infeksi Ice-icedan Epifit terhadap Pertumbuhan Eucheuma cottonii.Ilmu Kelautan,18 (1):1-6

Aslan, L.M. 1998. Budidaya Rumput Laut. Kanisius. Yogyakarta

Aslan,L.M., 1992, 1998. Budi Daya Rumput Laut. Kanissius. Yogyakarta.

Barus, T.A. 1996. Pengantar limnologi: studi tentang ekosistem air daratan. USU Press. Medan..

Djokosetyanto, D., I. Effendi \& K.I. Antara. 2008. Pertumbuhan Kappaphycus Alvarezii Varitas Maumere, Varitas Sacol Dan Eucheuma Denticulatum Di Perairan Musi, Buleleng. Ilmu Kelautan, 13 (3): 171-176.

Effendi., 2003. Telaah Kualitas Air.Bagi Pengelolaan Sumberdaya dan Lingkungan Perairan.Penerbit Kasinus (Anggota IKAPI), Yogyakarta.

Fitrian Tyani. 2015. Hama Penyakit (Ice-ice) Pada Budidaya Rumput Laut Studi kasus: Maluku Tenggara. Oseana XL (4): 1-10

Ghazali M., Husna H., Sukiman., 2018a, Diversitas dan Karakteristik Alga Merah (Rhodophyta) pada Akar Mangrove di
Teluk Serewe Kabupaten Lombok Timur, Jurnal Biologi Tropis, 18 (1) : 80-90.

Ghazali M., Nikmatullah A. 2015. IbM Desa Buwun Mas Sebagai Reinkarnasi Sentra Budidaya Rumput Laut Lombok Melalui Penerapan Teknologi Bondre. Laporan Pengabdian. Universitas Mataram.

Ghazali M., Rahmawati R., Astuti S.R., Sukiman, 2018b, Jenis Alga Merah (Rhodophyta) Pada Ekosistem Hutan Mangrove Di Dusun Ekas, Kabupaten Lombok Timur,Fish Scientiae, 8 (1 ) : 11-23.

Ghazali M., Kurnianingsih R., Astuti S.P., Fajar B.F., 2017, Keanekaragaman Makroalga Epifit Pada Makroalga Budidaya Pulau Lombok, Laporan Penelitian, Universitas Mataram

Global Invasive Species Database.2015a. Species Profile Acanthophora specifera.http://www.iucngisd.org/gisd/ species.php?sc=1060. Diakses tanggal 20 Oktober 2018.

Global Invasive Species Database.2015b. Species Profile Acanthophora specifera.http://www.iucngisd.org/gisd/ species.php?sc $=1060$. Diakses tanggal 20 Oktober 2018.

Harris, V. \& R. Stauffer. 2004. Cladophora Research And Management In The Great Lakes.Proceedings Of A Workshop Held At The GreatLakes Waterinstitute, University of Wisconsin-Milwaukee. United States Of America.

Kilar, J.A., and J. McLachlan. 1986. Ecological Studies of the Alga, Acanthophora spicifera (Vahl) Borg. (Ceramiales: Rhodophyta): Vegetative Fragmentation. J. Exp. Mar. Biol. Ecol. 104:1-21.

Kusumaningrum, B. D. 2008. Analisis Vegetasi Epifit di Area Wana Wisata Gonoharjo Kabupaten Kendal Provinsi Jawa Tengah. IKIP PGRI. Semarang.

Lundsor, E. 2002.Eucheuma Farming In Zanzibar.Thesis.University Of Bergen.

Nurdiana, Ma'ruf Kasim, Sarini Yusuf. 2016. Study Tentang Komposisi Jenis dan Keanekaragaman makroepifit pada Bududaya Rumput laut di Perairan Darawa Kecamatan Kaledupa Selatan Kabupaten Wakatobi.Jurnal Manajmen Sumber Daya Perairan. 1 (1): 93-98. 
Odum, P., E. 1971. Foundamental of ecology. W. B. Company and toppancompany. Lid. London.

Putinella, J.D., 2001. Evaluasi Lingkungan Budidaya Rumput Laut Di Teluk BagulaMaluku.http://www.coremap.or.id/d ownload/0121.pdf Diakses tanggal 25 Oktober 2017.

Rahman Abdul dan Magdalena, 2015,Kondisi Lingkungan Perairan dan Rumput Laut Kappaphycus alvarezii yang Dibudidayakan di Desa Jayakarsa, Kabupaten Minahasa Utara, Provinsi Sulawesi Utara.Jurnal Budidaya Perairan. 3( 1) : 93-100

Won YB, Cho TO,West JA. Fredericq S. 2015.Spyridia Filamentosa (Ceramiales, Rhodophyta): A Cosmopolitan Red Algal Species. Phycologia 44 (4).112-112.

WWF. 2014. Seri Panduan Perikanan Skala Kecil: Budidaya Rumput Laut. WWF. Jakarta.

Yulianto, K. 2004. Fenomena Faktor Pengontrol Penyebab Kerugian Pada Budidaya Karaginofit di Indonesia. Oseana, 2 (29): $17-23$. LIPI. 